\title{
The role of demand in fostering product vs process innovation: a model and an empirical test
}

\section{Herbert Dawid ${ }^{1}$. Gabriele Pellegrino² $\cdot$ Marco Vivarelli3,4,5 (iD}

Published online: 18 July 2020

(C) The Author(s) 2020

\begin{abstract}
While the extant innovation literature has provided extensive evidence of the so-called "demand-pull" effect, the possible diverse impact of demand evolution on product vs process innovation activities has not been yet investigated. This paper develops a formal model predicting a larger inducing impact of past sales in fostering product rather than process innovation. This prediction is then tested through a dynamic microeconometric model, controlling for R\&D persistence, sample selection, observed and unobservable individual firm effects and time and sectoral peculiarities. Results are consistent with the model and suggest that an expansionary economic policy may benefit the diffusion of new products or even the emergence of entire new sectors.
\end{abstract}

Keywords Technological change $\cdot \mathrm{R} \& \mathrm{D} \cdot$ Demand-pull innovation ·

Dynamic two tobit

\section{JEL Classification O31}

\section{Introduction}

Back in the Sixties and the Seventies, a vivid debate has occurred between the supporters of the technology-push approach and those underlining the crucial role of

The author are grateful for helpful comments from two anonymous referees.

Marco Vivarelli

marco.vivarelli@unicatt.it

1 Bielefeld University, Universitätsstraße 25, 33615 Bielefeld, Germany

2 College of Management of Technology, EPFL (Ecole Polytechnique Fédérale de Lausanne), Lausanne, Switzerland

3 Institute of Economic Policy, Università Cattolica del Sacro Cuore, Largo Gemelli 1, 20123, Milano, Italy

4 Institute for the Study of Labour (IZA), Bonn, Germany

5 UNU-MERIT, Maastricht, The Netherlands 
demand (demand-pull approach) in fostering and shaping innovation. While the former (see Rosenberg 1976, 1982; Freeman) focused on scientific and technological opportunities as necessary pre-conditions for a strongly path-dependent technological progress, the latter (Schmookler 1962; 1966; Meyers and Marquis 1990s) pointed out that market conditions were at least as much as important in creating the right incentives for innovation.

Analytically, the technology-push perspective calls for identifying innovation as an autoregressive process, where the essential role of previous knowledge is captured together with the cumulative, localized and persistent nature of technology (see Atkinson and Stiglitz 1969; Ruttan 1997; Antonelli 1998; Dosi et al. 2020) and where the specific sectoral technological opportunities are properly taken into account (see Malerba and Orsenigo 1996, 2005; Klepper and Thompson 2006; Capone et al. 2019).

Indeed, starting from the Eighties, innovation scholars have agreed that the technology-push and the demand-pull perspectives should be seen as complementary, since innovation is driven both by the intrinsic nature of science and technology and by market forces, primarily demand evolution (see Nelson and Winter 1982; Dosi 1988; Pavitt 2005; Toselli 2017; Di Stefano et al. 2012).

This paper will focus on the role of demand in differently affecting the incentives for product vs process innovation, albeit the proposed empirical test will fully take into account both the cumulative and persistent nature of innovation (represented by the an AR(1) specification of R\&D investment, see Section 3) and the role of sectoral peculiarities (captured by sectoral dummies, see Section 3 ).

Indeed, there are different arguments supporting the view that rising demand may induce an increase in firms' innovation efforts (see Schmookler 1962, 1966): firstly, increasing sales allow the financing of expensive R\&D and innovation activities (see Hall et al. 1999; O'Sullivan 2005); secondly, the introduction of innovation is strongly subject to uncertainty, which is reduced by optimistic demand conditions (see Fontana and Guerzoni 2008) ${ }^{1}$; thirdly, appropriability and potential profitability of innovation rise with market size (see Schumpeter 1942; Kamien and Schwartz 1982).

Previous literature has provided evidence supporting the demand-pull hypothesis both at the aggregate, sectoral and at the microeconomic (firm) level. The empirical debate started with the seminal contribution of Schmookler (1966), who - using US sectoral data - showed that the more investment there was in a user industry at a given time, the more patented capital goods innovation one observed in the supplying industry some time later. Scherer (1982) confirmed Schmookler's results, after checking for seven technology class dummies in the US; however, the consideration of differences in technological opportunities (a way to take into account the technology-push argument, see above) gave rise to a large increase in the fitness of his regressions, compared with the original ones put forward by Schmookler. Shifting the attention from patents to $R \& D$ investment (an ex-ante proxy of

\footnotetext{
${ }^{1}$ By making use of a sample of SMEs in different European countries, the authors empirically analyze the extent to which demand foster innovation by providing economic incentive and reducing uncertainty.
} 
innovation, overcoming a possible objection of endogeneity ${ }^{2}$ ) and using data on 46 Dutch sectors, Kleinknecht and Verspagen (1990) found evidence of a significant relationship between demand growth and R\&D growth. Indeed, the endogeneity and reverse causality problems in the relationship between demand and innovation may also affect the link between aggregate demand evolution and technological change at the macroeconomic level; however, Geroski and Walters (1995) - using macroeconomic time series for the UK - found significant evidence that output caused innovation and patents, but no evidence of the reverse effect. Most recent studies have focused on the level of the firm, using microdata. For instance, using Community Innovation Survey (CIS) data from about 8,000 Dutch firms, Brouwer and Kleinknecht (1996) found that demand growth induces an increase in innovation output, measured both in terms of products new to the firm and products new to the sector. In a later study, the same authors (Brouwer 1999) - using a panel of 441 Dutch firms - found a further confirmation of the demand-pull hypothesis. More recently, Piva and Vivarelli (2007) - using a longitudinal dataset of 216 Italian firms and controlling for the path-dependent nature of R\&D - found a significant role of sales in fostering R\&D, although this demand-pull effect turned out to be more or less effective according to different firm's characteristics.

However, previous theoretical and empirical analyses failed to fully investigate whether the demand-pull driver is more or less effective in inducing product vs process innovation. ${ }^{3}$

This is an interesting theoretical issue, since process and product innovation have different impacts, with the former more linked to productivity gains while the latter enlarging markets or even creating new ones. Therefore, the two kinds of innovations involve different macro- and micro-economic implications and so it is relevant to know which of the two is more likely to be accelerated by an increase in demand. Moreover, to disentangle the demand-pull effect between process and product innovation may be of some interest for policy makers, as well (see Nemet 2009; Peters

\footnotetext{
${ }^{2}$ Since there is generally a lag between innovation and final patenting, the time span - detected by Schmookler - between investment (sales) in the user industry and patenting in the supplying industry might actually correspond to a simultaneous occurrence of innovation and increasing sales within the firms in the supplying industry. Therefore, a key methodological problem may arise: it can be rightly argued that innovative activity itself increases demand because of the accelerator effects associated with decreasing prices due to process innovation and/or increasing market share due to product innovation. Thus, the high correlations between demand and innovative evolution discovered by Schmookler might be affected by an endogeneity problem and actually pointing to a reverse causality between innovation and demand. If R\&D expenditures are used instead of patents (as in the present study), this problem does not arise, since R\&D expenditures will give raise to innovation in a later period.

${ }^{3}$ One relevant exception is the study of Guerzoni (2010). The author proposes a theoretical model evaluating the impact that two specific components of demand (market size and users' sophistication) have upon both process and product innovation. He finds that these components have a different impact on the aggregate industry innovative output: the market size has always a positive effect on both product and process innovation, while the impact of an increase in the degree of sophistication is negative in the case of process innovation and uncertain in the case of product innovation. Although similar in its aim, our model significantly departs from the model put forward in Guerzoni (2010), since in our model firms compete in output (a la Cournot) while in Guerzoni (2010) the type of competition is in price (a la Bertrand). Furthermore, our model takes into account how the temporal dimension may influence the competitive environment and, consequently, firm's innovative behaviour.
} 
et al. 2012). For instance, if demand is more important for product innovation and diffusion rather than for process innovation, governments may indeed play a role in promoting an economic policy combining a Keynesian perspective (increasing demand) with a Schumpeterian one (promoting those strands of demand fostering the introduction and diffusion of new products in emerging and high-tech sectors).

This paper will try to fill this gap in the extant literature. Intuitively, process innovation are basically cost-cutting and so - although positively affected by demand evolution - they should be profitable in any case, while product innovation should be promoted and introduced only when demand perspectives are particularly promising. The second section of this paper will feature a formal model developing this intuition and indeed predicting a larger inducing impact of past sales in fostering product rather than process innovation. This theoretical prediction will be tested in Section 3, using a unique longitudinal micro-dataset. Section 4 will briefly conclude and discuss some policy implications.

\section{The model}

We consider an industry model, where $n_{f}$ firms compete by offering a standard product. They can reduce their marginal production costs for that product by means of process innovation and can also invest in product innovation. Upon successful product innovation they add a horizontally and vertically differentiated product to their product range and produce this new product in addition to the standard one. It is assumed that the new product is a (partial) substitute of the old product. Two periods, $t=1,2$ are considered, where at $t=1$ firms first engage in Cournot competition based on their current marginal production costs for the standard product $c_{i, 1}^{s}, i=1, . ., n$ and then determine their investment in process and product innovation activities. At $t=2$ firms engage again in Cournot competition based on their new production costs, and in case of a successful innovation at $t=1$ on the extended product range. Firms choose product and process innovation expenditures in order to maximize expected profit in period $t=2$ net of effort costs and in their optimization rely on naive expectations about the costs and product range of their competitors. In particular, firm $i$ assumes that none of the competitors introduces a new product in $t=0$ and also that $c_{j, 2}^{s}=c_{j, 1}^{s}$ for all $j \neq i$.

The inverse demand function for the standard product is given by

$$
p_{t}^{s}=\alpha-\beta \sum_{j=1}^{n} q_{j, t}^{s}, \quad \beta>0,
$$

if no other product is offered, with $q_{i, t}^{s}$ denoting the firms' output quantity in period $t=1,2$. The parameter $\alpha>0$ captures the strength of demand on the considered market. In case a new product is introduced in period $t=1$, then in $t=2$ the inverse demand system is

$$
\begin{aligned}
& p_{2}^{s}=\alpha-\beta \sum_{j=1}^{n} q_{j, 2}^{s}-\gamma q_{i, 2}^{n} \\
& p_{2}^{n}=\alpha+\theta-\beta q_{i, 2}^{n}-\gamma \sum_{j=1}^{n} q_{j, 2}^{s},
\end{aligned}
$$


where $q_{i, 2}^{n}$ denotes the output quantity the innovating firm $i$ chooses for the new product, $\gamma \in[0, \beta]$ governs the degree of horizontal differentiation between the standard and the new product and $\theta \geq 0$ determines the degree of vertical differentiation. Marginal production costs for the new product are denoted by $c_{i, 2}^{n}$. We assume that a firm's efficiency in the production process for the new product is closely related to that firm's efficiency in producing the standard product, which implies that, comparing costs across firms, $c_{i, 2}^{n}$ should be closely correlated to $c_{i, 1}^{s}$. Hence, we assume that $c_{i, 2}^{n}=\xi c_{i, 1}^{s}$ for some $\xi>1 .^{4}$

Process innovation effort by firm $i$, denoted by $x_{i, 1}$, reduces marginal production costs for the established product. In particular, we assume that

$$
c_{i, 2}^{s}=\operatorname{Max}\left[c_{i, 1}^{s}-\delta x_{i, 1}, 0\right]
$$

and the costs of process innovation are given by $\chi\left(x_{i, 1}\right)=\frac{\eta}{2} x_{i, 1}^{2}$. The parameter $\eta$ is assumed to be sufficiently large to guarantee that the optimal process innovation effort satisfies $x_{i, 1} \leq \frac{c_{i, 1}}{\delta}$ for all $i$.

The probability for a successful product innovation is given by $\min \left[a y_{i, 1}, 1\right]$ with $a>0$ and $y_{i, 1}$ denoting the product innovation effort. Analogous to process innovation we also assume quadratic costs of product innovation given by $\zeta\left(y_{i, 1}\right)=$ $\frac{\kappa}{2} y_{i, 1}^{2}$.

Standard calculations yield that the quantity of firm $i$ in the Cournot equilibrium at $t=1$ is given by ${ }^{5}$

$$
q_{i, 1}^{s *}=\frac{\alpha-n c_{i, 1}^{s}+C_{-i, 1}^{s}}{\beta(n+1)},
$$

where $C_{-i, 1}^{s}=\sum_{j \neq i} c_{j, 1}^{s}$. Taking into account that firm have naive expectations about the costs of the competitors the expected quantity and payoff of firm $i$ in $t=2$ in the absence of a product innovation read

$$
q_{i, 2}^{s, N I}=\frac{\alpha-n\left(c_{i, 1}^{s}-\delta x_{i, 1}\right)+C_{-i, 1}^{s}}{\beta(n+1)}, \quad \pi_{i, 2}^{N I}=\frac{\left(\alpha-n\left(c_{i, 1}^{s}-\delta x_{i, 1}\right)+C_{-i, 1}^{s}\right)^{2}}{\beta(n+1)^{2}} .
$$

Under the condition that the new product is introduced by firm $i$ the quantities in the Cournot equilibrium are

$$
\begin{aligned}
q_{i, 2}^{s, I} & =\frac{\left.2 \alpha\left(\beta^{2}-\gamma^{2}\right)+(n+1) \gamma(\alpha \gamma-\beta(\alpha+\theta))-\left(2 n \beta^{2}-(n-1) \gamma^{2}\right)\left(c_{i, 1}^{s}-\delta x_{i, 1}\right)+2\left(\beta^{2}-\gamma^{2}\right) C_{-i, 1}\right)+(n+1) \beta \gamma \xi c_{i, 1}^{s}}{2 \beta\left(\beta^{2}-\gamma^{2}\right)(n+1)}, \\
q_{i, 2}^{n, I} & =\frac{\beta(\alpha+\theta)-\alpha \gamma-\beta \xi c_{i, 1}^{s}+\gamma\left(c_{i, 1}^{s}-\delta x_{i, 1}\right)}{2\left(\beta^{2}-\gamma^{2}\right)} .
\end{aligned}
$$

The expected profit of the firm under this condition is given by

$$
\pi_{i, 2}^{I}=q_{i, 2}^{s, I}\left(p_{2}^{s}-c_{i, 1}^{s}+\delta x_{i, 1}\right)+q_{i, 2}^{n, I}\left(p_{2}^{n}-\xi c_{i, 1}^{s}\right),
$$

\footnotetext{
${ }^{4}$ For reasons of simplicity it is assumed here that cost reductions due to process innovation for the standard product carried out in period $t=1$ do not have an instantaneous effect on the production costs of the simultaneously introduced new product.

${ }^{5}$ In what follows we restrict attention to cases where all firms produce positive quantities in the Cournot equilibrium.
} 
where $p_{2}^{s}, p_{2}^{n}$ are determined according to Eq. 1. Overall, firm $i$ chooses its innovation activities in period $t=1$ such that the following expected profit function is maximized:

$$
\pi_{i}\left(x_{i, 1}, y_{i, 1}\right)=\left(1-\min \left[a y_{i, 1}, 1\right]\right) \pi_{i, 2}^{N I}+\min \left[a y_{i, 1}, 1\right] \pi_{i, 2}^{I}-\chi\left(x_{i, 1}\right)-\zeta\left(y_{i, 1}\right)
$$

For the extreme cases where the effectiveness of either process innovation or product innovation activities are zero the optimal innovation profiles can be characterized analytically.

Proposition 1 If no product innovation is possible, i.e. $a=0$, then the optimal profile of innovation effort is given by

$$
x_{i, 1}^{*}=\frac{2 \delta n(n+1)}{\beta \eta(n+1)^{2}-2 \delta^{2} n^{2}} q_{i, 1}^{s *}, \quad y_{i, 1}^{*}=0 .
$$

If no process innovation is possible, i.e. $\delta=0$, then the optimal profile of innovation effort is given by

$$
x_{i, 1}^{*}=0, \quad y_{i, 1}^{*}=\frac{a\left(\beta^{2}-\gamma^{2}\right)}{\kappa \beta}\left(q_{i, 2}^{n, I}\right)^{2} .
$$

The Proposition (the proof of which is provided in the Appendix A2) shows that in industries dominated by process innovation we should expect a linear relationship between past sales and innovation effort, whereas for product innovators incentives for engaging in such activities are positively related to the firm's expected sales of the new product. Since the strength of demand affects sales of the standard as well as the new product, this relationship suggests a positive relationship also between past sales and product innovation effort. It is important to stress that in our setup the relationship between innovation effort and past sales emerges through an expectation channel and is not based on an ex-ante assumption that innovation expenditures are a (fixed) fraction of current profits. This allows us to capture the demand-pull effect on innovation and also to distinguish between the nature of the relationship between past sales and product versus process innovation activities.

To obtain a testable outcome in terms of a possible diversified effect of the demand-pull over the incentive to spend in innovation activities separately for product and process innovation (see next section), in what follows we consider the elasticity of innovation effort with respect to past sales if the dynamics of sales is triggered by a variation the strength of demand $\alpha .{ }^{6}$ More formally, we define

$$
\epsilon_{i}^{p r o c}=\frac{\partial x_{i, 1}^{*}}{\partial q_{i, 1}^{s *}} \frac{q_{i, 1}^{s *}}{x_{i, 1}^{*}}=\frac{\partial x_{i, 1}^{*}}{\partial \alpha} / \frac{\partial q_{i, 1}^{s *}}{\partial \alpha} \frac{q_{i, 1}^{s *}}{x_{i, 1}^{*}}
$$

\footnotetext{
${ }^{6}$ Alternatively, one could consider the elasticity of innovation effort with respect to past sales if the dynamics of sales of firm $i$ is triggered by a variation of its competitiveness, expressed by the marginal costs $c_{i, 1}^{s}$. We have carried out the entire analysis also for elasticities based on a variation of the parameter $c_{i, 1}^{s}$ and there are no qualitative differences between the results obtained in that case and the ones reported below.
} 
and

$$
\epsilon_{i}^{p r o d}=\frac{\partial y_{i, 1}^{*}}{\partial q_{i, 1}^{s *}} \frac{q_{i, 1}^{s *}}{y_{i, 1}^{*}}=\frac{\partial y_{i, 1}^{*}}{\partial \alpha} / \frac{\partial q_{i, 1}^{s *}}{\partial \alpha} \frac{q_{i, 1}^{s *}}{y_{i, 1}^{*}} .
$$

In light of the quadratic costs functions of both types of innovation activities it is clear that the elasticity of the process respectively product innovation expenditures with respect to past sales is given by $2 \epsilon_{i}^{\text {proc }}$ and $2 \epsilon_{i}^{\text {prod }}{ }^{7}$ Since we are mainly interested in the relative size of the two, we stick in our analysis to the consideration of the elasticities of innovation effort.

From Proposition 1 we obtain immediately that the elasticity of process innovation effort for the special case without product innovation is given by $\epsilon_{i}^{\text {proc }}=1$, whereas in the absence of process innovation the elasticity of product innovation effort can be calculated as

$$
\epsilon_{i}^{\text {prod }}=\frac{2\left(\alpha-n c_{i, 1}^{s}+C_{-i, 1}^{s}\right)}{\alpha+\frac{\beta}{\beta-\gamma} \theta-\frac{\xi \beta-\gamma}{\beta-\gamma} c_{i, 1}^{s}} .
$$

Clearly, also this elasticity is positive and whether it is smaller or larger than the elasticity of process innovation in principle depends on the characteristics of the considered market and of firm $i$. However, several general observations can be made. Taking into account that $\xi>1$, it follows that in a market in which (first period) production costs for the standard product are symmetric across firms, i.e. $C_{-i, 1}^{s}=(n-1) c_{i, 1}^{s}$, the elasticity of product innovation with respect to past sales is larger than one, and therefore larger than the elasticity of process innovation, if the vertical differentiation of the new product is small, i.e. if $\theta$ is close to zero. The elasticity of product innovation of firm $i$ decreases for an increasing degree of vertical differentiation of the new product $\theta$. Also an increase of the marginal production costs of the firm, $c_{i, 1}^{s}$, induces a decrease of the elasticity of product innovation with respect to past sales as long as degree of horizontal differentiation between the standard and the new product is sufficiently high, i.e. $\beta-\gamma$ is not too small.

The intuition for these observations follows from the expressions for optimal product and process innovation efforts given in Proposition 1. Since process innovation reduces unit costs for the standard product, the incentives to invest are proportional to past sales, which are the estimator for future sales. Expected profits resulting from the introduction of a new product are convex in the market size for the new product. This market size is positively linked to the overall strength of demand and hence the firm's expectation about the market size increases with the size of past sales. Hence, the product innovation effort, which increase the probability to be able to introduce the new product, is convex in past sales and the elasticity of effort with respect to past sales tends to be larger for product than for process innovation.

To get more detailed insights into the factors that determine the sizes of these two elasticities we rely on a numerical analysis. We carry out this analysis for the case in which firm $i$ engages either in product ot in process innovation (i.e. $\epsilon_{i}^{\text {prod }}$ is given by

\footnotetext{
${ }^{7}$ To link our theoretical with empirical analysis we consider product and process innovation expenditures as equivalent to the $R \& D$ expenditures of firms engaged in product respectively process innovation in the empirical analysis of Section 3 .
} 


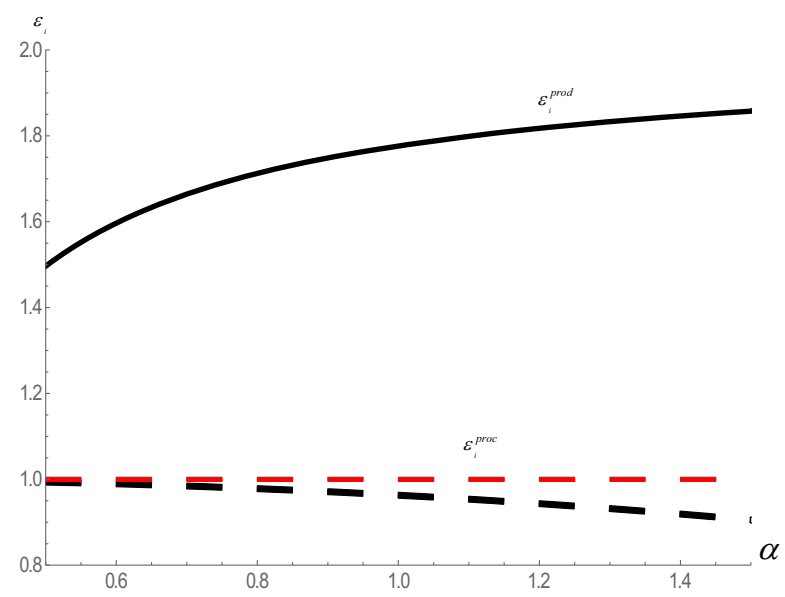

Fig. 1 Elasticity of product innovation (solid line) and process innovation (dashed) effort with respect to first period sales for $\alpha \in[0.5,1.5]$ (red lines: only product or only process innovation; black lines: general case)

Eq. 5 and $\epsilon_{i}^{\text {prod }}=1$ ) as well as for the general case, in which firm $i$ engages in both product and process innovation ${ }^{8}$.

In Fig. 1 we show the two elasticities for varying strength of demand $\alpha{ }^{9}$ Both in this figure and in Fig. 2 red lines show the elasticities for the scenario where firm $i$ engages either in product or in process innovation, whereas the black lines correspond to the general case where the firm does both. In particular for the product innovation elasticity often only the black line can be seen because the elasticities in the two scenarios almost coincide. Figure 1 shows that the elasticities with respect to past sales for product and process innovation are positive, but the elasticity of product innovation activities is larger than that of process innovation activities. The gap between the elasticities becomes larger as the strength of demand increases. Hence, this figure confirms that our conclusions from Proposition 1, that the elasticity of product innovation tends to be larger than that of process innovation carries over also for firms that simultaneously engage in both type of innovation activities.

To check the robustness of these findings, in Fig. 2 we explore how the elasticities of the two types of innovation activities depend on different key model parameters. With respect to the strength of demand we now always assume that the reservation

\footnotetext{
${ }^{8}$ For the case with both types of innovative activities an analytical characterization of the relationship between past sales and innovation expenditures is no longer possible.

${ }^{9}$ The parameter setting used in this illustration is $n=5, \beta=0.2, \gamma=0.1, \theta=0.15, \delta=0.1, a=$ $0.7, \eta=1.5, \kappa=5, C_{-i, 1}^{s}=0.8, c_{i, 1}^{s}=0.2, \xi=1.5$. This setting has been chosen to generate equilibrium outcomes that are compatible with empirically plausible stylized facts. In particular, under this parameter setting the Lerner Index for the standard product in equilibrium is $\left(p_{1}^{s}-c_{i, 1}^{s}\right) / p_{1}^{s}=0.4$ and the $\mathrm{R} \& \mathrm{D}$ intensity is about $11 \%$, where $\mathrm{R} \& \mathrm{D}$ expenditures are approximately evenly distributed between product and process innovation. Hence, we consider a rather innovative oligopolistic industry, in which firms have substantial market power.
} 


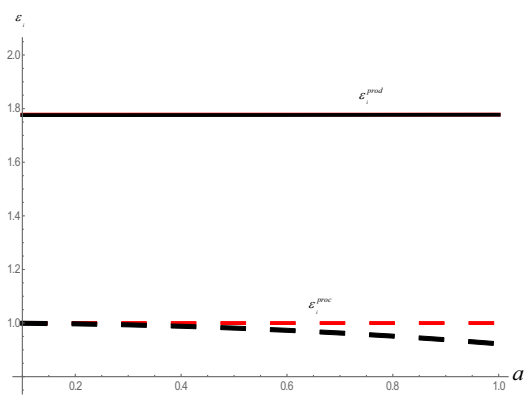

(a)

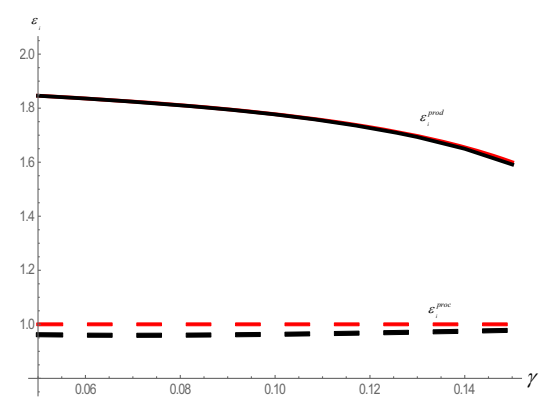

(c)

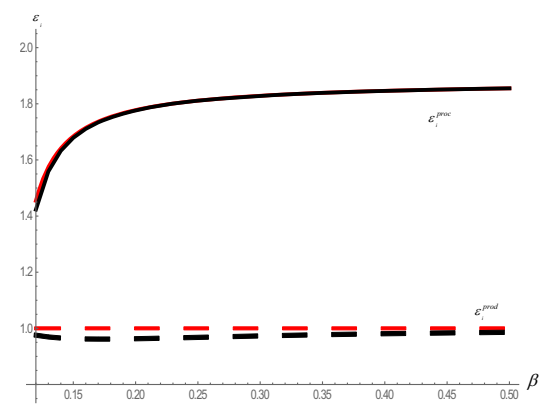

(e)

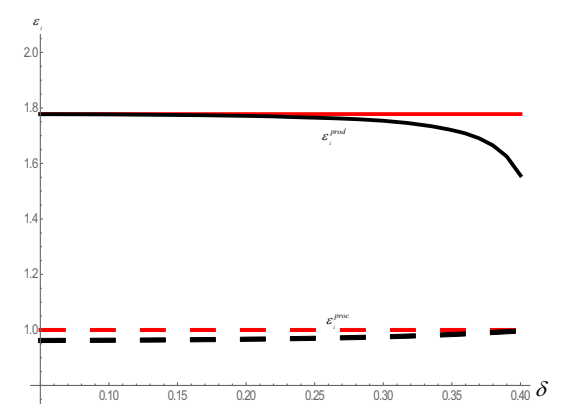

(b)

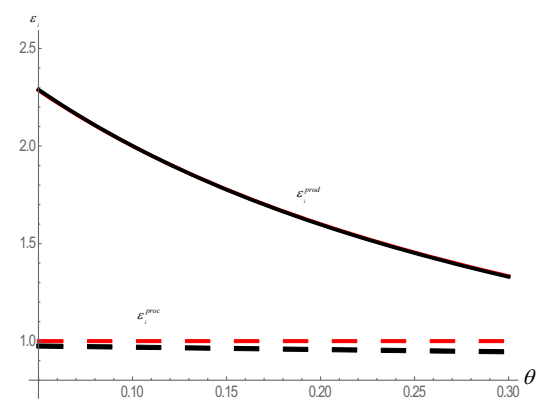

(d)

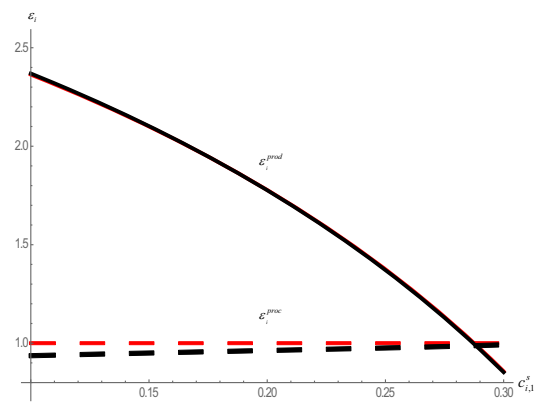

(f)

Fig. 2 Elasticity of product innovation (solid line) and process innovation (dashed) expenditures for a variation of the effectiveness of product innovation (a), effectiveness of process innovation (b), degree of horizontal differentiation (c), vertical differentiation (d), slope of the inverse demand (e) and marginal production costs of the considered firm (f). Red lines: only product or only process innovation; black lines: general case

price parameter is given by $\alpha=1$. In the two panels in the first row the effect of changes in the effectiveness of product and process innovation is considered, in the two panels in the second row the parameters for horizontal and vertical product differentiation between the new and the standard product are varied and in the third row we explore the effect of changing the slope of the inverse demand function and the production costs of firm $i$. 
It can be clearly seen that the effectiveness of product and process innovation has almost no influence on the elasticity of product and process innovation effort with respect to past sales. The degree of horizontal and vertical differentiation of the new from the standard product has some influence. In particular, as predicted also in our analytical considerations above, the elasticity of product innovation activities becomes smaller the more strongly vertically differentiated the new product is. Intuitively, such an increase in differentiation increases the product innovation expenditures of the firm without increasing the sales or profits of the firm in period $t=1$. In such a scenario, where the fraction of period 1 profits spent for innovation is particularly high, the change of innovation expenditures induced by an increase of $\alpha$ is relatively small compared to the total innovation expenditures. Therefore the elasticity of expenditures with respect to past sales is relatively small. Whether an increase in the degree of horizontal differentiation, i.e. a decrease of $\gamma$, increases or decreases the expected profit of product innovation depends on the degree of vertical differentiation. For small values of $\theta$ this expected profit goes up, whereas for large values of $\theta$ the expected profit from a new product introduction becomes larger the lower the degree of horizontal differentiation of the new product is. Hence, it depends on the size of $\theta$ whether the elasticity of product innovation expenditures increases or decreases with $\gamma$. For the default parameter setting depicted in Fig. 2, the degree of vertical differentiation is sufficiently strong such that the elasticity decreases with $\gamma$. We have verified numerically that this relationship indeed turns around if $\theta$ is smaller. However, in any case the elasticity of product innovation is larger than that of process innovation. Due to essentially the same arguments just discussed with respect to changes of $\gamma$, also the monotonicity of the elasticity with respect to the slope of the inverse demand, $\beta$, depends on the size of $\theta$. For the default scenario the elasticity is increasing in $\beta$, whereas it is decreasing for small values of $\theta$.

If we vary production costs of the considered firm, $c_{i, 1}^{s}$, then this has the strongest effect on the elasticities of innovation effort among all parameter variations. The elasticity of product innovation decreases substantially as $c_{i, 1}^{s}$ increases, but for the elasticity of process innovation for firm $i$ to be larger than that of product innovation the firm's production costs have to be close to $c_{i, 1}^{s}=0.3$, which is $50 \%$ higher than the average costs in the industry. For such a large cost value the firm's profit on the established market are so low that the ratio of $\mathrm{R} \& \mathrm{D}$ expenditures to profit would be close to above 1 , which seems to be an extreme value. Hence, also in this respect the observation that product innovation investments react more sensitively to demand variations than process innovation investments is confirmed for the empirically relevant parameter range.

Coming back to the comparison of the elasticities of product and process innovation activities between the cases where the firm engeges only in one or in both types of innovation, we conclude from Figs. 1 and 2 that the elasticitiy of product innovation is indeed almost identical between the two scenarios for all parameter constellations with the exception of large values of the process innovation efficiency $\delta$ (see Fig. 2(b)). If the firm is only investing in product innovation, then of course the elasticity of this activity is not affected by $\delta$, whereas for a firm engaged in both activities the elasticity of product innovation decreases as the efficiency of process innovation grows. The elasticity of process innovation activities is always lower if 
the firm engages in both innovation activities compared to a scenario where it only invests in process innovation. Intuitively, for a firm which also invests in product innovation an increase in market demand $\alpha$ induces higher product innovation investments, which in turn has a negative impact on the inventive to invest in process innovation. Hence, for such a firm product innovation investments react less strongly to an increase in $\alpha$ compared to a firm which is not engaged in product innovation.

On the whole, key predictions of our theoretical model are that the elasticities of both types of innovation activities with respect to past sales are positive and that, with the exception of firms characterized by particularly high R\&D intensities, we expect that the elasticity of product innovation expenditures is larger than that of process innovation expenditures. Recalling the discussion in Section 1, our model predicts a positive and significant impact of the demand-pull on the expenditures addressed to both product and process innovation. However, this effect is expected to be significantly larger in the case of product rather than process innovation.

To put our theoretical results into perspective with respect to the literature, we should compare them to those of Cohen and Klepper (1996a), who consider a framework where (under certain conditions) the ratio of process to product innovation increases with the firm's ex-ante output. Although, they do not explicitly consider elasticities, their results imply that the elasticity of product innovation with respect to past sales is below that of process innovation, and therefore qualitatively differ from our findings. To understand these diverging results, it is important to realize that their notion of product innovation is one of an addition of product features. The additional features increase the willingness to pay of existing consumers and leads to a fixed number of new consumers, which is assumed to be independent from the past sales quantity. Based on this, in their setup the incentive for product innovation closely resembles that for process innovation and increases in a concave way with past sales. Conversely, in our model product innovation (with some probability) leads to the market introduction of an additional differentiated product, the demand of which is closely linked to 'total market demand' and hence the expected profit from the sales of this new product is actually convex with respect to the past sales. This is the main reason for the difference in our findings. Clearly, both aspects, quality improvement and the extension of the product range, are important drivers of product innovation such that both models capture relevant aspects of product innovation. Which aspect should be considered dominant is an empirical question and our empirical analysis in the following section gives some indication in that respect.

\section{The empirical evidence}

The unique database used in this study is based on the Encuesta Sobre Estrategias Empresariales (ESEE), a survey on business strategies which has been run yearly since 1990 by the SEPI foundation, on behalf of the Spanish Ministry of Industry. This survey comprises extensive information on about 2,000 companies, with a focus on innovation activity. Based on longitudinal data, the survey is characterized by the systematic tracking of changes in firms' characteristics (such as changes of 
legal status, mergers, splitting, acquisitions, etc.), in order to check the information provided by the firms and to preserve their reliability and consistency over time.

The adopted sampling procedure in designing the ESEE ensures representativeness for each two-digit NACE-CLIO manufacturing sector, following both exhaustive (firms with more than 200 employees, equal to 715 in 1990) and random sampling criteria (specifically, in 1990 a sample of 1,473 firms employing between 10 and 200 employees was built, using a stratified, proportional, restricted and systematic sampling method with a random start). Furthermore - in order to guarantee a persistent level of representativeness and to preserve the inference properties - start-up companies have been incorporated in the survey year by year, according to the same random sampling criteria. ${ }^{10}$

In this study, we consider ESEE data for the period 1991 to 2012. The original longitudinal dataset - once taken into account missing information and the occurrence of mergers and acquisitions - comprised 36,032 observations. Then, given the purpose of this study, we restricted our attention to the firms engaged in process and/or product innovation, ending up with an unbalanced panel of 13,815 observations. ${ }^{11}$

The proposed specification tests the demand-pull hypothesis through the link between current R\&D expenditures and our key regressor (sales) lagged one period. Figure A1 presents a preliminary descriptive illustration of this relationship; as can be seen, it shows a clear positive correlation between lagged sales and current R\&D expenditure, supporting the demand-pull perspective adopted in this study.

As far as the technology-push hypothesis is concerned (see Section 1), the role of firm's knowledge stock is taken into account by the inclusion of the lagged dependent variable. Controls include: 1) firm's size (measured through employment) - since larger firms are more likely to have their own R\&D department performing formalized R\&D activities and should be less constrained in financing costly and uncertain R\&D investments, while SMEs mainly rely on non-R\&D types of innovation (see Cohen and Levin 1989, 1996b, 2010; Expósito and Sanchis-Llopis; 2) firm's age, since more experienced incumbents are more likely to massively invest in R\&D (see Huergo and Jaumandreu 2004; Artés 2009; Pellegrino and Piva 2020; 3) company's belonging to a business group (dummy variable), since firms taking part to a business group have more opportunities to share the uncertainty implied by innovation activities (see Filatotchev et al. 2003; 4) year and sectoral dummies, the latter taking into account sector-specific technological opportunities (see Section 1). Therefore, our econometric test will be based on the following specification:

$$
\begin{aligned}
R \& D_{i, t}= & c+\beta_{1} \operatorname{lnR}_{2} \mathrm{D}_{\mathrm{i}, \mathrm{t}-1}+\beta_{2} \operatorname{lnSales}_{\mathrm{i}, \mathrm{t}-1}+\beta_{3} \operatorname{lnEmp}_{\mathrm{i}, \mathrm{t}}+\beta_{4} \ln _{\operatorname{lge}_{\mathrm{i}, \mathrm{t}}} \\
& +\beta_{5} \operatorname{Group}_{\mathrm{i}, \mathrm{t}}+\left(\delta_{i}+\epsilon_{i, t}\right) .
\end{aligned}
$$

where $\delta_{i}$ is the time-invariant unobserved individual effect and $\epsilon_{i, t}$ is the idiosyncratic error term.

\footnotetext{
${ }^{10}$ Many studies have used ESEE as a reliable data source and provide evidence of its representativeness (see, for instance, González et al. 2005; López 2008).

${ }^{11}$ Table 2 in the Appendix A1 shows the structure of the unbalanced panel; as can be seen, time coverage is sufficiently uniform.
} 
However, as common in innovation studies, the explanation of $R \& D$ expenditures has to take into account both the autoregressive (dynamic) nature of such expenditures (see Section 1) through the inclusion of the lagged dependent variable and the occurrence of sample selection in between those firms engaging in R\&D and those that are inactive (see Crepon et al. 1998; Mohnen and Hall 2013). Therefore, eq. 1 should be split into a binary selection equation - where the choice to engage in $\mathrm{R} \& \mathrm{D}$ is investigated - and a main equation where the intensity of $\mathrm{R} \& \mathrm{D}$ investment is explained. The resulting simultaneous two-equation model has been tested through a dynamic type- 2 tobit estimator, recently proposed by Raymond et al. (2010).

Using a notation similar to Raymond et al. (2010)[p. 499], we thus have:

$$
\begin{gathered}
d_{i, t}=1\left[\rho \mathrm{d}_{\mathrm{t}-1}+\delta^{\prime} \mathrm{Z}_{\mathrm{i}, \mathrm{t}}+\alpha_{1 i}+\epsilon_{1 i, t}>0\right], \\
y_{i, t}= \begin{cases}\delta \mathrm{y}_{\mathrm{i}, \mathrm{t}}+\beta^{\prime} \mathrm{X}_{\mathrm{i}, \mathrm{t}}+\alpha_{2 i}+\epsilon_{2 i, t} & \text { if } d_{i t}=1 \\
0, & \text { if } d_{i t}=0,\end{cases}
\end{gathered}
$$

Equation 7 is the selection equation and it models the discrete strategic decision of firm $i$ to invest in R\&D activities (or not) as a function of its past R\&D decision $\left(d_{t-1}\right)$, a battery of explanatory variables $\left(Z_{i, t}\right)$, time-invariant unobserved individual effects $\left(\alpha_{1 i}\right)$ and an idiosyncratic error term $\left(\epsilon_{1 i, t}\right)$. The main equation (8) represents the subsequent decision of the innovative firm i (conditional on: $d_{t}=1$ ) on how much to invest in R\&D as a function of its past $\mathrm{R} \& \mathrm{D}$ expenditures $\left(y_{i, t}\right)$, its characteristics $\left(X_{i, t}\right)$, time-invariant unobserved individual fixed effects $\left(\alpha_{2 i}\right)$ and an idiosyncratic error term $\left(\epsilon_{2 i, t}\right)$ independent of $X_{i, t}$. The simultaneous estimation of the two dynamic equations (7) and (8) has to take into account three key methodological problems: firstly, the occurrence of sample selection; secondly, the presence of unobserved firm's specific individual effects; thirdly, the possible correlation between the initial conditions and the individual effects, since the first observation referring to a dynamic variable is also determined by the same data generation process.

Indeed, (Raymond et al. 2010) propose an estimator that jointly solves these problems; in particular, the individual error terms, $\left(\alpha_{1 i}\right)$ and $\alpha_{2 i}$, are assumed to have a joint distribution and a random-effects approach is put forward. Moreover, the problem associated with the initial conditions is taken into account assuming that the unobserved firm-specific effects depend on the initial conditions and on the exogenous variables ${ }^{12}$ :

$$
\begin{aligned}
& a_{1, i}=b_{1}^{0}+b_{1}^{1} \mathrm{~d}_{\mathrm{i} 0}+b_{1}^{\prime 2} \mathrm{Z}_{\mathrm{i}}+u_{1 i}, \\
& a_{2, i}=b_{2}^{0}+b_{2}^{1} \gamma_{\mathrm{i} 0}+b_{2}^{\prime 2} \mathrm{X}_{\mathrm{i}}+u_{2 i},
\end{aligned}
$$

where $b_{1}^{0}$ and $b_{2}^{0}$ are constants, $d_{i 0}$ and $\gamma_{i 0}$ are the initial values of the dependent variables and $Z_{i}$ and $X_{i}$ are Mundlak (1978) within-means of $Z_{i t}$ and $X_{i t}$.

Furthermore, to properly take into account sample selection, Eqs. 7 and 8 are jointly estimated through a conditional maximum likelihood estimator and are correlated

\footnotetext{
${ }^{12}$ As qualified by Raymond et al. (2010)[p. 500], this solution - dealing with this specific aspect of the adopted model - was originally put forward by Wooldridge (2005).
} 
through the individual effects $\left(\rho_{u 1, u 2} \neq 0\right)$ and the idiosyncratic error terms $\left(\rho_{\epsilon 1, \epsilon 2} \neq\right.$ $0)$. In particular, the 'overall' correlation between the two equations turns out to be:

$$
\rho_{t o t}=\frac{\rho_{u 1, u 2} \sigma_{\mathrm{u} 1} \sigma_{\mathrm{u} 2}+\rho_{\epsilon 1, \epsilon 2} \sigma_{\epsilon 2}}{\sqrt{\left(\sigma_{u 1}^{2}+1\right)\left(\sigma_{\mathrm{u} 2}^{2}+\sigma_{\epsilon 2}^{2}\right)}}
$$

Turning our attention back to the estimation of eq. 6 and taking into account what discussed in Section 1 and what put forward through the model illustrated in the previous section, we expect: 1) consistently with the technology-push approach, a positive and significant coefficient of the lagged dependent variable in all the estimates; 2) consistently with the demand-pull approach, an overall support of past sales as a driver of innovation (that is a positive and significant coefficient in all the estimates); 3) however, consistently with our model, the magnitude of this latter effect is expected to be larger for the product-only innovators rather than for the process-only innovators (that is a coefficient larger and possibly more significant in the case of companies exclusively devoted to product innovation); 4) consistently with the extant literature (see above) a confirmation of the positive links between company's size, age and group belonging on the one side and R\&D investment on the other side (that is positive and significant coefficients: $\beta_{3}, \beta_{4}$ and $\beta_{5}$ ).

Table 1 reports the econometric results for the whole sample and separately for those firms only engaged in process innovation and those only engaged in product innovation. ${ }^{13}$

As can be seen, the lagged dependent variable is positive and highly significant (99\% level of confidence) all over the different estimates and both in the selection and in the main equation; this is a further proof of the auto-regressive nature of the $\mathrm{R} \& \mathrm{D}$ investment and it is fully consistent with the technology-push hypothesis.

Also consistent with the extant literature are the outcomes concerning the role of firm's size, age and group belonging in spurring innovation, at least as far as the main equation and the entire sample are concerned. ${ }^{14}$

Turning our attention to the main focus of this work and looking at the entire sample, the demand-pull hypothesis appears to be supported at least as the main equation is concerned: while past sales positively (but not significantly) affect the decision to invest in R\&D, they significantly (at $99 \%$ of statistical confidence) increase the amount spent in $\mathrm{R} \& \mathrm{D}$ expenditures.

However, consistently with the prediction of our model (see previous section), this latter effect is obviously larger in the case of the firms only engaged in product innovation (elasticity equal to 0.277 ), rather than in their counterparts only engaged in process innovation (elasticity equal to 0.129 ). Moreover, the coefficient is significant at the $99 \%$ level of confidence in the product-only case and only at the $95 \%$ level in the process-only one. Finally, the statistical significance of the difference between the two estimated coefficients account at $90 \%$ (t-statistics equal to 1.75). Taken together, these outcomes offer a considerable support to the prediction of our model: indeed,

\footnotetext{
${ }^{13}$ Descriptive statistics of all included variables are provided in the Appendix A1 (Table 3).

${ }^{14}$ Therefore, our results further support a well-established interpretation, which underlines that R\&D policies (e.g. R\&D subsidies) mainly affect larger, mature and interconnected companies.
} 
Table 1 Results from the dynamic type 2 tobit estimates

\begin{tabular}{|c|c|c|c|c|c|c|}
\hline & \multicolumn{2}{|l|}{ Total } & \multicolumn{2}{|l|}{ Only Process } & \multicolumn{2}{|l|}{ Only Product } \\
\hline \multicolumn{7}{|l|}{ Selection equation } \\
\hline $\mathrm{R} \& \mathrm{D}$ dummy $\mathrm{t}-1$ & $1.806^{* * * *}$ & $(0.066)$ & $2.038 * * *$ & $(0.082)$ & $2.312 * * *$ & $(0.143)$ \\
\hline Ln Sales t-1 & 0.040 & $(0.046)$ & 0.014 & $(0.058)$ & 0.043 & $(0.093)$ \\
\hline Ln emp t-1 & $0.242 * * *$ & $(0.057)$ & $0.285^{* * *}$ & $(0.071)$ & 0.126 & (0.110) \\
\hline Ln Age & 0.067 & $(0.044)$ & 0.050 & $(0.052)$ & $0.177 * *$ & $(0.082)$ \\
\hline Group & -0.003 & $(0.079)$ & 0.075 & $(0.095)$ & 0.050 & $(0.152)$ \\
\hline Constant & $-3.251 * * *$ & $(0.324)$ & $-3.164 * * *$ & $(0.371)$ & $-2.238 * * *$ & $(0.633)$ \\
\hline $\mathrm{N}$ of Obs & 13,815 & & 7,226 & & 2,383 & \\
\hline \multicolumn{7}{|l|}{ Main Equation } \\
\hline $\ln (\mathrm{R} \& \mathrm{D}$ exp. $) \mathrm{t}-1$ & $0.225^{* * *}$ & $(0.014)$ & $0.314 * * *$ & $(0.021)$ & $0.320 * * *$ & $(0.024)$ \\
\hline Ln Sales t-1 & $0.271 * * *$ & $(0.039)$ & $0.129 * *$ & $(0.053)$ & $0.277 * * *$ & $(0.066)$ \\
\hline Ln emp t-1 & $0.313^{* * *} *$ & $(0.047)$ & $0.446 * * *$ & $(0.064)$ & $0.233 * * *$ & $(0.080)$ \\
\hline Ln Age & $0.075^{* *}$ & $(0.037)$ & 0.038 & $(0.048)$ & -0.032 & $(0.058)$ \\
\hline Group & $0.197 * * *$ & $(0.055)$ & 0.079 & $(0.080)$ & $0.217 * *$ & $(0.089)$ \\
\hline Constant & $-2.109 * * *$ & $(0.267)$ & $-1.816^{* * *}$ & $(0.357)$ & $-1.668 * * *$ & $(0.407)$ \\
\hline $\mathrm{N}$ of Obs & 7,853 & & 3,037 & & 1,508 & \\
\hline \multicolumn{7}{|l|}{ Extra Parameters } \\
\hline In.con. (R\&D dummy) & $0.567 * * *$ & $(0.090)$ & $0.507 * * *$ & $(0.107)$ & $0.366^{* *}$ & $(0.160)$ \\
\hline In.con. (Ln R\&D) & $0.098 * * *$ & $(0.012)$ & $0.091 * * *$ & $(0.016)$ & $0.053 * * *$ & $(0.019)$ \\
\hline$\rho_{u 1 u 2}$ & $0.147^{* *}$ & $(0.071)$ & $0.149 *$ & $(0.081)$ & -0.129 & $(0.135)$ \\
\hline$\rho_{\epsilon 1 \epsilon 1}$ & $0.456^{* * *}$ & $(0.052)$ & $0.575 * * *$ & $(0.072)$ & $0.676^{* * *}$ & $(0.118)$ \\
\hline$\sigma_{u 1}$ & $-0.669 * * *$ & $(0.105)$ & $-0.654 * * *$ & $(0.151)$ & $-0.796 * *$ & $(0.347)$ \\
\hline$\sigma_{u 2}$ & $-0.520 * * *$ & $(0.043)$ & $-0.567 * * *$ & $(0.073)$ & $-0.674 * * *$ & $(0.084)$ \\
\hline$\sigma_{\epsilon 2}$ & $-0.055 * * *$ & $(0.016)$ & -0.034 & $(0.025)$ & $-0.142 * * *$ & $(0.032)$ \\
\hline
\end{tabular}

Notes: Standard errors in brackets. ***, ** and * indicate significance at $1 \%, 5 \%$ and $10 \%$ level, respectively. All regressions include time and industries dummies (results available upon request)

the demand-pull effect is overall important, but stronger when product innovation is involved.

\section{Conclusion}

Consistently with the most updated view put forward by innovation scholars, this study provides further evidence that both the technology-push and the demandpull hypotheses play an important role in explaining innovation activities, here represented by the R\&D expenditures.

However, the extant literature does not provide any clue about the possible diverse impact of demand evolution on product vs process innovation activities. This paper fills this gap and proposes a formal model where past sales foster both product and 
process innovation expenditures, but with the product elasticity systematically larger than the process one.

This theoretical prediction is tested through a dynamic microeconometric model controlling for autocorrelation in R\&D, sample selection, observed and unobservable individual firm effects and time and sectoral peculiarities. Results are consistent with the model and reveal a larger impact of past sales over the product innovative expenditures rather than the process ones.

This outcome has an important policy implication. Indeed, policy makers should be aware that the demand-pull leverage is particularly crucial for product innovation. Therefore, if the diffusion of new products or even the emergence of entire new sectors are assumed as targets, a tailored expansionary policy might be seen as a proper and effective strategy.

Funding Information Open Access funding provided by Università Cattolica del Sacro Cuore within the CRUI-CARE Agreement.

\section{Compliance with Ethical Standards}

Conflict of interests The authors declare that they have no conflict of interest.

Open Access This article is licensed under a Creative Commons Attribution 4.0 International License, which permits use, sharing, adaptation, distribution and reproduction in any medium or format, as long as you give appropriate credit to the original author(s) and the source, provide a link to the Creative Commons licence, and indicate if changes were made. The images or other third party material in this article are included in the article's Creative Commons licence, unless indicated otherwise in a credit line to the material. If material is not included in the article's Creative Commons licence and your intended use is not permitted by statutory regulation or exceeds the permitted use, you will need to obtain permission directly from the copyright holder. To view a copy of this licence, visit http://creativecommonshorg/licenses/by/4.0/.

\section{Appendix A1) Descriptive statistics}

Table 2 Descriptive statistics: structure of the unbalanced panel

\begin{tabular}{lll}
\hline Year & Freq. & Perc. \\
\hline 1991 & 859 & 6.22 \\
1992 & 785 & 5.68 \\
1993 & 695 & 5.03 \\
1994 & 704 & 5.10 \\
1995 & 601 & 4.35 \\
1996 & 602 & 4.36 \\
1997 & 729 & 5.28 \\
1998 & 701 & 5.07 \\
1999 & 645 & 4.67 \\
2000 & 736 & 5.33 \\
2001 & 554 & 4.01 \\
2002 & 509 & 3.68 \\
2003 & 346 & 2.50 \\
2004 & 365 & 2.64 \\
2005 & 559 & 4.05
\end{tabular}


The role of demand in fostering product vs process innovation:...

Table 2 (continued)

\begin{tabular}{lll}
\hline Year & Freq. & Perc. \\
\hline 2006 & 594 & 4.30 \\
2007 & 729 & 5.28 \\
2008 & 661 & 4.78 \\
2009 & 647 & 4.68 \\
2010 & 689 & 4.99 \\
2011 & 540 & 3.91 \\
2012 & 565 & 4.09 \\
Total & 13,815 & 100.00 \\
\hline
\end{tabular}

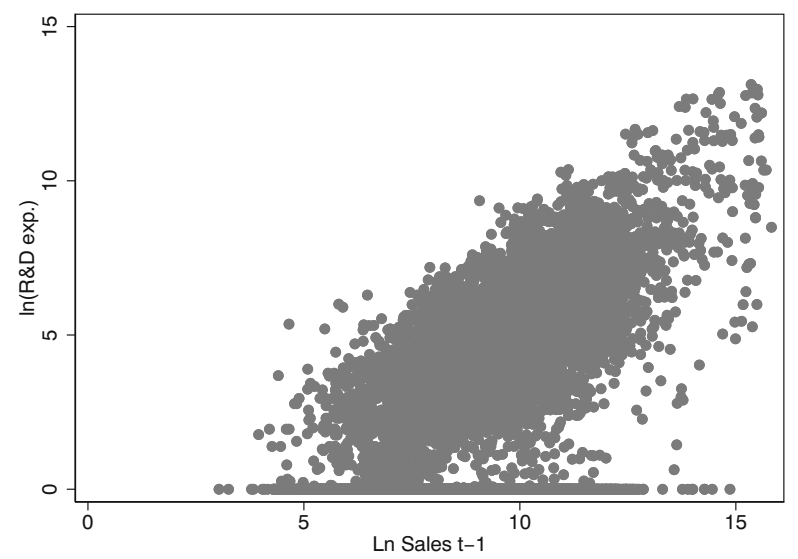

Fig. 3 Descriptive statistics: relationship between R\&D expenditure and lagged sales (scatter plot)

Table 3 Descriptive statistics: mean and standard deviation (in brackets)

\begin{tabular}{llll}
\hline & Total sample & Only Proc. & Only Prod. \\
\hline R\&D dummy & 0.57 & 0.42 & 0.63 \\
& $(0.50)$ & $(0.49)$ & $(0.48)$ \\
ln(R\&D exp.) & 2.98 & 2.08 & 3.18 \\
& $(3.01)$ & $(2.78)$ & $(2.86)$ \\
R\&D dummy t-1 & 0.55 & 0.42 & 0.60 \\
& $(0.50)$ & $(0.49)$ & $(0.49)$ \\
ln(R\&D exp.) t-1 & 2.93 & 2.10 & 3.03 \\
& $(3.02)$ & $(2.80)$ & $(2.86)$ \\
Ln Sales t-1 & 9.08 & 8.81 & 8.73 \\
Ln emp t-1 & $(1.94)$ & $(1.89)$ & $(1.88)$ \\
& 4.60 & 4.39 & 4.31 \\
Ln Age & $(1.48)$ & $(1.42)$ & $(1.42)$ \\
& 3.07 & 3.00 & 3.09 \\
Group & $(0.83)$ & $(0.84)$ & $(0.80)$ \\
& 0.39 & 0.35 & 0.35 \\
N & $(0.49)$ & $(0.48)$ & $(0.48)$ \\
& 13,815 & 7,226 & 2,383 \\
\hline
\end{tabular}




\section{Appendix A2) Proof of Proposition 1}

Assume first that $a=0$. Under this assumption the firm's objective function reduces to

$$
\pi_{i}\left(x_{i, 1}, y_{i, 1}\right)=\pi_{i, 2}^{N I}-\xi\left(x_{i, 1}\right)-\zeta\left(y_{i, 1}\right)
$$

and therefore obviously $y_{i, 1}=0$ is optimal. Maximizing with respect to $x_{i, 1}$ we obtain the first order condition

$$
\frac{\partial \pi_{i}}{\partial x_{i, 1}}=\frac{2 n \delta}{n+1}\left(q_{i, 1}^{s *}+\frac{\delta n}{\beta(n+1)} x_{i, 1}\right)-\eta x_{i, 1}=0
$$

Solving for $x_{i, 1}$ yields the expression for $x_{i, 1}^{*}$ in the first part of the Proposition.

Considering the case where $\delta=0$, it follows directly that $x_{i, 1}^{*}=0$. The first order condition with respect to $y_{i, 1}$ is given by

$$
\frac{\partial \pi_{i}}{\partial y_{i, 1}}=a \Delta \pi_{i, 2}-\kappa y_{i, 1}=0,
$$

where $\Delta \pi_{i, 2}=\pi_{i, 2}^{I}-\pi_{i, 2}^{N I}$. Using Eqs. 2, 3 and 4 it is easy to check that for $x_{i, 1}=0$ we have

$$
q_{i, 2}^{s, N I}=q_{i, 1}^{s *}=q_{i, 2}^{s, I}+\frac{\gamma}{\beta} q_{i, 2}^{n, I} .
$$

Considering the best reply quantities of the competitors of firm $i$, it is easy to see that the above equality implies that the competitors' output is identical in the cases with and without product innovation by firm $i$, i.e.

$$
\sum_{j \neq i} q_{2, j}^{s, I}=\sum_{j \neq i} q_{2, j}^{s, N I}=\frac{(n-1) \alpha+(n-1) c_{i, 1}^{s}-2 C_{-i, 1}^{s}}{\beta(n+1)} .
$$

Together, these observations directly imply that $p_{1}^{s}=p_{2}^{s, N I}=p_{2}^{s, I}$.

Therefore, the difference in profit for firm $i$ between the scenarios without and with product innovation can be rewritten as

$$
\begin{aligned}
\Delta \pi_{i, 2} & =\left(q_{i, 2}^{s, I}-q_{i, 2}^{s, N I}\right)\left(p_{1}^{s}-c_{i, 1}^{s}\right)+q_{i, 2}^{n, I}\left(p_{2}^{n, I}-c_{i, 2}^{n}\right) \\
& =q_{i, 2}^{n, I}\left(-\frac{\gamma}{\beta}\left(p_{1}^{s}-c_{i, 1}^{s}\right)+\left(p_{2}^{n, I}-\xi c_{i, 1}^{s}\right)\right) \\
& =\frac{\left(\beta^{2}-\gamma^{2}\right)}{\beta}\left(q_{i, 2}^{n, I}\right)^{2} .
\end{aligned}
$$

The last equality above follows from the first order conditions of the firm with respect to $q_{i, 1}^{s}$ and $q_{i, 2}^{n, I}$ which imply $\left(p_{1}^{s}-c_{i, 1}^{s}\right)=\beta q_{i, 1}^{s}$ and $p_{2}^{n, I}-\xi c_{i, 1}^{s}=\gamma q_{i, 2}+\beta q_{i, 2}^{n, I}$ and Eq. 12.

\section{References}

Antonelli C (1998) The dynamics of localized technological changes. The interaction between factor costs inducement, demand pull and schumpeterian rivalry. Econ Innov Technol 6:97-120

Artés J. (2009) Long-Run Versus Short-Run decisions: R\&D and market structure in spanish firms. Res Policy 38:120-132

Atkinson AB, Stiglitz JE (1969) A new view of technological change. Econ J 79:573-578 
Brouwer E, Kleinknecht A (1996) Firm size, small business presence and sales of innovative products: a Micro-Econometric analysis. Small Bus Econ 8:189-201

Brouwer E (1999) Note and Comment. Keynes-plus? Effective Demand and Changes in Firm-Level R\&D: An Empirical Note. Camb J Econ 23:385-399

Capone G, Malerba F, Nelson RR, Orsenigo L, Winter SG (2019) History friendly models: Retrospective and future perspectives. Eur Bus Rev 9:1-23

Cohen WM, Levin RC (1989) Empirical studies of innovation and market structure. Handb Ind Organ 2:1059-1107

Cohen WM, Klepper S (1996a) Firm size and the nature of innovation within industries: the case of process and product R\&D. Rev Econ Stat 78:232-243

Cohen WM (1996b) A reprise of size and R\&D. Econ J 106:925-951

Cohen WM (2010) Fifty Years of Empirical Studies of Innovative Activity and Performance, Handbook of the economics of innovation. Elsevier

Crepon B, Duguet E, Mairesse J (1998) Research, innovation and productivity: an econometric analysis at the firm level. Econ Innov Technol 7:115-158

Di Stefano G, Gambardella A, Verona G (2012) Technology push and demand pull perspectives in innovation studies: Current findings and future research directions. Res Policy 41:1283-1295

Dosi G (1988) Sources, procedures, and microeconomic effects of innovation. J Econ Lit 26:1120-1171

Dosi G, Marengo L, Nuvolari A (2020) Institutions and economic change: Some notes on SelfOrganization, power and learning in human organizations. Eur Bus Rev 10:1-22

Expósito A, Sanchis-Llopis JA (2019) The Relationship between Types of Innovation and SMEs' Performance: A Multi-Dimensional Empirical Assessment. Eur Bus Rev 9:115-135

Filatotchev I, Piga C, Dyomina N (2003) Network positioning and R\&D activity: a study of italian groups. R\&D Manag 33:37-48

Fontana R, Guerzoni M (2008) Incentives and uncertainty: an empirical analysis of the impact of demand on innovation. Camb J Econ 32:927-946

Freeman C (1982) The Economics of Industrial Innovation. Pinter

Geroski PA, Walters CF (1995) Innovative activity over the business cycle. Econ J 105:916-928

González X., Jaumandreu J, Pazo C (2005) Barriers to innovation and subsidy effectiveness. RAND J Econ 36:930-949

Guerzoni M (2010) The impact of market size and users' sophistication on innovation: the patterns of demand. Econ Innov Technol 19:113-126

Hall B. H., Mairesse J, Branstetter L, Crepon B (1999) Does Cash Flow Cause Investment and R\&D?: An Exploration Using Panel Data for French, Japanese, and United States Scientific Firms. In: Audretsch DB, Thurik R (eds) Innovation, Industry Evolution and Employment. Cambridge University Press, Cambridge, pp 129-56

Huergo E, Jaumandreu J (2004) How Does Probability of Innovation Change with Firm Age? Small Bus Econ 22:193-207

Kamien MI, Schwartz N (1982) Market structure and innovation. Cambridge University Press, Cambridge Kleinknecht A, Verspagen B (1990) Demand and innovation: Schmookler Re-Examined. Res Policy 19:387-394

Klepper S, Thompson P (2006) Submarkets and the evolution of market structure. RAND J Econ 37:861886

López A (2008) Determinants of R\&D cooperation: Evidence from spanish manufacturing firms. Int J Ind Organ 26:113-136, 00239

Malerba F, Orsenigo L (1996) The dynamics and evolution of industries. Ind Corp Chang 5:51-87

Malerba F (2005) Sectoral systems of innovation: a framework for linking innovation to the knowledge base, structure and dynamics of sectors. Econ Innov Technol 14:63-82

Meyers S, Marquis D (1990s) (1969): Successful Industrial Innovation: Critical Factors For the. National Science Foundation, Washington

Mohnen P, Hall BH (2013) Innovation and productivity: an update. Eur Bus Rev 3:47-65

Mundlak Y (1978) On the pooling of time series and cross section data. Econometrica 46:69-85

Nelson RR, Winter SG (1982) An evolutionary theory of economic change. The Belknap Press of Harvard University Press, Cambridge

Nemet GF (2009) Demand-Pull, Technology-Push, And Government-Led incentives for Non-Incremental technical change. Res Policy 38:700-709 
O'Sullivan M (2005) Finance and Innovation. In: Fagerberg J, Mowery DC, Nelson RR (eds) The Oxford Handbook of Innovation. Oxford University Press, Oxford, pp 240-265

Pavitt K (2005) Innovation Processes. In: Fagerberg J, Mowery DC, Nelson RR (eds) The Oxford Handbook of Innovation. Oxford University Press, Oxford, pp 86-114

Pellegrino G, Piva M (2020) Innovation, Industry and Firm Age: Are There New Knowledge Production Functions? Eur Bus Rev 10:65-95

Peters M, Schneider M, Griesshaber T, Hoffmann VH (2012) The Impact of Technology-Push and Demand-Pull Policies on Technical Change - Does the Locus of Policies Matter? Res Policy 41:1296-1308

Piva M, Vivarelli M (2007) Is Demand-Pulled Innovation Equally Important in Different Groups of Firms? Camb J Econ 31:691-710

Raymond W, Mohnen P, Palm F, van der Loeff SS (2010) Persistence of Innovation in Dutch Manufacturing: Is It Spurious? Rev Econ Stat 92:495-504

Rosenberg N (1976) Perspectives on technology. Cambridge University Press, Cambridge

Rosenberg N (1982) Inside the black box: Technology and economics. Cambridge University Press, Cambridge

Ruttan VW (1997) Induced innovation, evolutionary theory and path dependence: Sources of technical change. Econ J 107:1520-1529

Scherer FM (1982) Demand-Pull And technological invention: Schmookler revisited. J Ind Econ 30:22537

Schumpeter JA (1942) Capitalism socialism and democracy. Harper and Brothers, New York

Schmookler J (1962) Economic sources of inventive activity. J Econ History 22:1-20

Schmookler J (1966) Invention and economic growth. Harvard University Press, MA

Toselli M (2017) Knowledge Sources and Integration Ties toward Innovation. A Food Sector Perspective. Eur Bus Rev 7:43-65

Wooldridge JM (2005) Simple solutions to the initial conditions problem in dynamic, nonlinear panel data models with unobserved heterogeneity. J Appl Econom 20:39-54

Publisher's note Springer Nature remains neutral with regard to jurisdictional claims in published maps and institutional affiliations. 